\title{
Revalorisation of rapeseed pomace extracts: An in vitro study into its anti-oxidant and DNA protective properties
}

\author{
Franziska Pohl ${ }^{a}$, Marie Goua ${ }^{a}$, Giovanna Bermano ${ }^{b}$, Wendy R. Russell ${ }^{c}$, Lorraine Scobbie ${ }^{c}$, \\ Patrícia Maciel $^{\text {d,e }}$, Paul Kong Thoo Lin ${ }^{\mathrm{a}, *}$ \\ a School of Pharmacy and Life Science, Robert Gordon University, Aberdeen AB10 1GJ, Scotland, United Kingdom \\ ${ }^{\mathrm{b}}$ Centre for Obesity Research and Education (CORE), Robert Gordon University, Aberdeen AB10 1GJ, Scotland, United Kingdom \\ ${ }^{\mathrm{c}}$ Rowett Institute of Nutrition and Health, University of Aberdeen, AB25 2ZD, Scotland, United Kingdom \\ ${ }^{\mathrm{d}}$ Life and Health Sciences Research Institute (ICVS), School of Medicine, University of Minho, Braga, Portugal \\ e ICVS/3B's - PT Government Associate Laboratory, Braga/Guimarães, Portugal
}

\section{A R T I C L E I N F O}

\section{Article history:}

Received 16 March 2017

Received in revised form 12 May 2017

Accepted 21 June 2017

Available online 23 June 2017

\section{Keywords:}

Rapeseed pomace

Soxhlet extraction

Reducing capacity (FC)

Phenolics

Radical scavenging activity (DPPH)

Ferric iron reducing antioxidant power

(FRAP)

Oxygen-radical absorbance capacity assay

(ORAC)

pBR322 plasmid DNA

\begin{abstract}
A B S T R A C T
Rapeseed pomace (RSP) is a waste product obtained after edible oil production from Brassica napus. Analysis of ubiquitous secondary metabolites in RSP samples (two breeds, harvested in 2012/2014 respectively from North East of Scotland) and their ethanol/water (95:5) Soxhlet extracts were carried out. Soxhlet extraction of the RSP (petroleum ether followed by $95 \%$ ethanol) gave a solid extract. LCMS/MS data of the extracts revealed several secondary metabolites, with Sinapic acid being the most abundant. Strong antioxidant activities of the Soxhlet extracts were confirmed from the results obtained in the FRAP, DPPH and ORAC assays. Furthermore, for the very first time, RSP extracts $(13.9 \mu \mathrm{g} / \mathrm{ml})$ provided complete DNA protection, from oxidative stress induced by AAPH $(3.5 \mathrm{mM})$. Therefore the strong antioxidant and DNA protecting properties demonstrated by the RSP extracts in this study warrants further investigation for their revalorisation and potential use as reliable source of antioxidants in different food applications.
\end{abstract}

(c) 2017 Elsevier Ltd. All rights reserved.

\section{Introduction}

Food sustainability and food waste management have become more important with the ever growing world population. Ways to revalorize food waste/by-products are of great interest. With global population augmenting, the demand on food production increases continuously. Food waste has been found to be a complex reservoir of carbohydrates, proteins, lipids, as well as micronutrients (Ravindran \& Jaiswal, 2016). Vine trimming waste, for example, has been found to be useful for the production of natural food additives (Portilla, Rivas, Torrado, Moldes, \& Domínguez, 2008). Recently the potential use of plant by-products in the diet has become a subject of great interest, with the aim to find and apply exogenous antioxidants in the food industry. Some of the agricultural by-products that have shown to contain well known antioxidants, such as phenolics, are for example fruit and vegetable

\footnotetext{
* Corresponding author.

E-mail address: p.kong@rgu.ac.uk (P. Kong Thoo Lin).
}

waste (Wijngaard, Rößle, \& Brunton, 2009), olive pomace (Palmieri et al., 2012) and grape seed pomace (Jara-Palacios et al., 2013).

Another source of agricultural by-products is pomace/meal/ cake from rapeseed (Brassica napus; Cruciferae), a crop continuously rising in demand for the production of oil, as a food source. The oil is high in $\alpha$-linolenic acid, giving it a low ratio of omega - 6/omega - 3 fatty acids, making it a good source of oil for human consumption (Kortesniemi et al., 2015). Rapeseed oil, previously used for the energy industries and non-food use, is now one of the top three oilseeds worldwide (Lin et al., 2013). However, increasing production leads to the accumulation of a higher amount of solid rapeseed waste/by-product, called rapeseed pomace (RSP) or rapeseed cake/meal. Currently this by-product is used as an addition to livestock feed and is sold on for a considerable, but fluctuating, price. There might be opportunities to improve its commercial value by looking at its various constituents with the view of isolating bioactive compounds, which could be used as food additives beneficial for human health or in food preserving measurements. 
In 2004, Thiyam et al. reported the potential use of RSP extracts in preventing lipid oxidation in rapeseed oil. This was proposed due to the significant amount of phenolic compounds present in RSP. Suggestions were made to use RSP extracts to stabilize oils or other food products, which would give the by-product a large contribution to the plant meal industry (Thiyam, Kuhlmann, Stöckmann, \& Schwarz, 2004). A more recent review (Szydłowska-Czerniak, 2013) on bioactive compounds from rapeseed and its products describes the presence of many biologically active compounds, such as tocols, phytosterols, phospholipids and phenolic compounds, which have been found to show significant antioxidant properties, suggesting their potential use in the food, pharmaceutical or cosmetic industry (Saeidnia \& Gohari, 2012; Szydłowska-Czerniak, 2013). Up to now, mostly RSP originating from countries in continental Europe (Germany, France and Poland), China, India and Canada has been studied. Although those studies had focused on the nature and properties of the bioactive compounds in RSP, there has not been any report yet on the DNA protective effect of RSP extracts.

Therefore, the aims of the present work were to study for the first time (i) the secondary metabolite content of RSP and RSP extracts (Soxhlet) from two different breeds, one harvested in 2012 and the other in 2014, originating from the northeast of Scotland; (ii) the antioxidant properties of the RSP extracts from both breeds/years; (iii) the protective properties of RSP extracts on DNA when exposed to AAPH (2,2'-azobis (2-amidinopropane hydrochloride, a free radical generator often used in biological studies (Wei, Zhou, Cai, Yang, \& Liu, 2006)) to determine the potential for revalorisation of RSP.

\section{Materials and methods}

\subsection{Chemicals}

1,1-Diphenyl-2-picryl-hydrazyl (DPPH), methanol (HPLC grade), gallic acid, Trolox, Folin \& Ciocalteu's phenol reagent, sodium acetate trihydrate, 2,4,6-Tris(2-pyridyl)-s-triazine (TPTZ), hydrochloric acid $(\mathrm{HCl})$, ferric chloride, sodium carbonate $\left(\mathrm{Na}_{2} \mathrm{CO}_{3}\right)$, sodium hydroxide $(\mathrm{NaOH}), \mathrm{AAPH}, \mathrm{KH}_{2} \mathrm{PO}_{4}$, EDTA, Sodium fluorescein and SA were obtained from Sigma-Aldrich; glacial acetic acid, ethanol, Tris-base, pBR322 Plasmid DNA $(0.5 \mu \mathrm{g} / \mu \mathrm{l})$, petroleum ether (bp $40-60^{\circ} \mathrm{C}$ ), agarose, sodium sulphate (anhydrous) and Phosphate Buffered Saline (PBS) Tablets (Dulbecco A, OXOID Limited) from Fisher Scientific; GelRed ${ }^{\mathrm{TM}}$ Nucleic Acid Gel Stains $10000 \times$ in water (Biotium) was from VWR.

\subsection{Plant material}

The RSP utilized throughout this project was provided by Mackintosh of Glendaveny (Mains of Buthlaw, Glendaveny, Peterhead), Scotland. Two RSP samples were obtained, one breed harvested in 2012 and a different breed harvested in 2014 and stored in plastic bags at $-80^{\circ} \mathrm{C}$ upon arrival.

Before extraction the pomace samples were individually ground in a coffee grinder (De Longhi KG39) to a particle size between 710 and $125 \mu \mathrm{m}$ and then freeze dried (Edwards, Freeze Dryer Modulyo). Ground dried samples were kept at $-20^{\circ} \mathrm{C}$ until extraction (short term storage).

\subsection{Methods overview}

A method's overview is given in Fig. 1. Two methods of extraction were used, ethyl acetate and Soxhlet extracts were characterised via LC-MS/MS analysis. The Soxhlet extracts were taken forward for further antioxidant/radical scavenging activity as well as DNA protective property analysis.

\subsection{Rapeseed pomace secondary metabolite analysis}

\subsubsection{General}

To characterise the major secondary metabolites (free and bound fractions) an extraction on freeze-milled (Spex 6700, Edison) pomace samples was used, determining free (FA), bound (alkali (ALK)- and acid labile (ACD)) metabolites using extraction

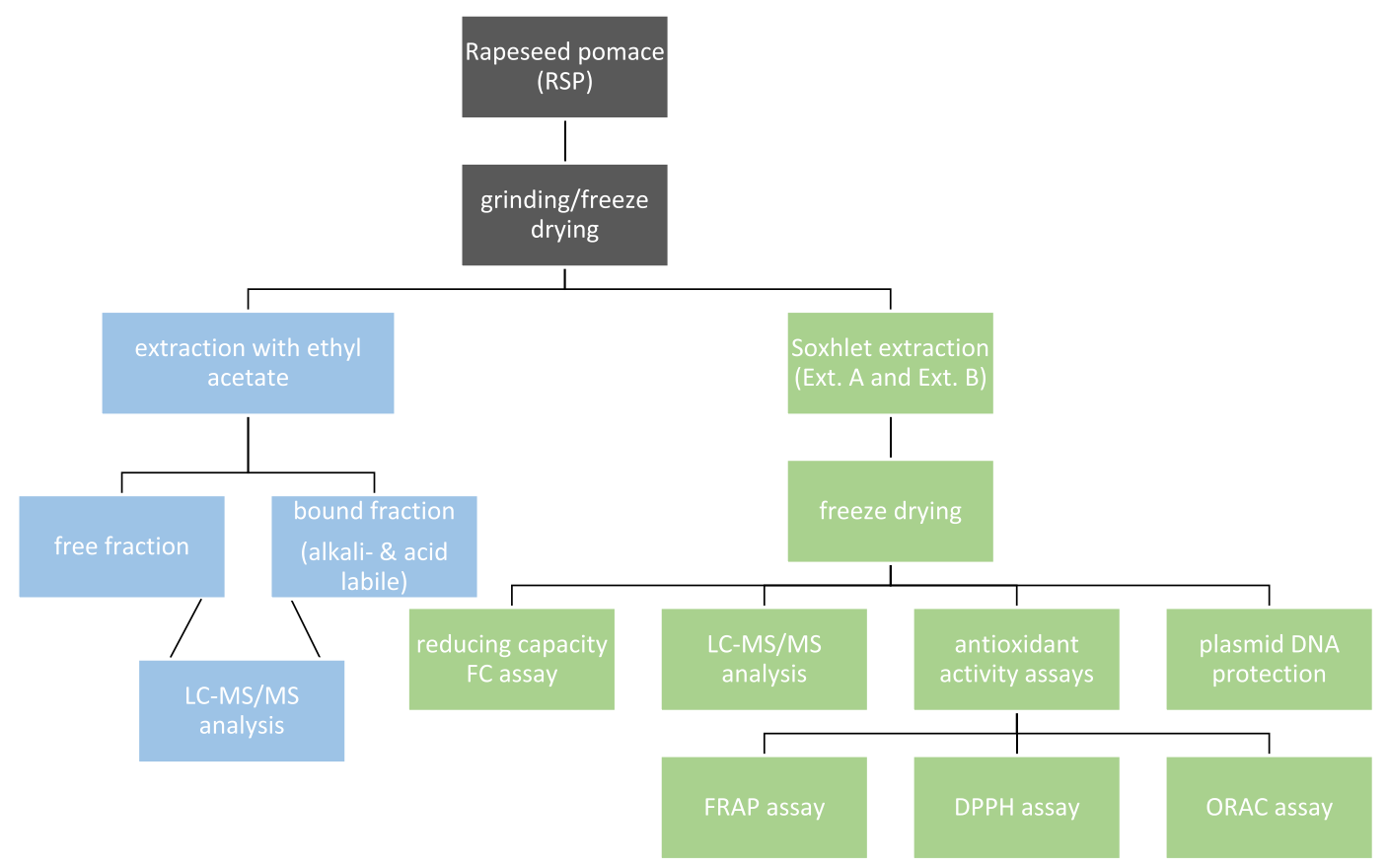

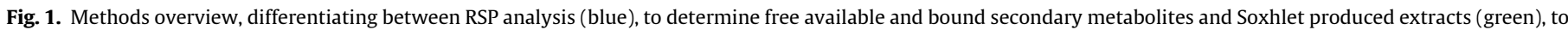

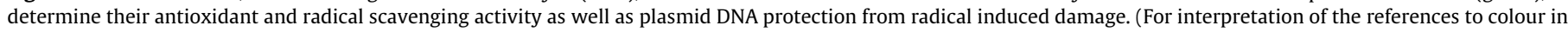
this figure legend, the reader is referred to the web version of this article.) 
processes previously described (Russell, Labat, Scobbie, Duncan, \& Duthie, 2009).

\subsubsection{Free acids}

In brief, RSP sample ( $0.1 \mathrm{~g}$ dry weight) was suspended in $\mathrm{HCl}$ $(0.2 \mathrm{M} ; 3 \mathrm{ml})$ followed by the addition of ethyl acetate (EtOAc; $5 \mathrm{ml}$ ). The mixture was shaken, vortexed and sonicated for $5 \mathrm{~min}$, followed by centrifugation $\left(1800 \mathrm{~g} ; 5 \mathrm{~min} ; 18^{\circ} \mathrm{C}\right)$. The EtOAc layer was collected and filtered into a round bottom flask $(50 \mathrm{ml})$, by passing through Whatman No 1 filter paper containing a small amount of sodium sulphate (anhydrous). This process was repeated two more times, with a final centrifugation (3200g; $10 \mathrm{~min} ; 18^{\circ} \mathrm{C}$ ). The solvent in the round bottom flask was removed via a rotary evaporator at temperatures not exceeding $40^{\circ} \mathrm{C}$. Samples were stored in a desiccator until preparation for analysis. The remaining aqueous fraction (obtained after the EtOAc extraction) was neutralised ( $\mathrm{pH}$ 6.5-7.0) using $\mathrm{NaOH}(4 \mathrm{M})$, frozen and then freeze dried.

\subsubsection{Alkali-labile phenolic acids}

To the freeze dried aqueous fractions, $\mathrm{NaOH}(1 \mathrm{M} ; 3 \mathrm{ml})$ was added and stirred at room temperature for $4 \mathrm{~h}$ under nitrogen, then the $\mathrm{pH}$ was reduced to $\mathrm{pH} 2$ with $\mathrm{HCl}(10 \mathrm{M})$. The fraction was then extracted with EtOAc $(5 \mathrm{ml})$, shaken, vortexed and sonicated ( $5 \mathrm{~min}$ ). The solvent (EtOAc) layers were separated by centrifugation (1800g; $\left.5 \mathrm{~min} ; 18^{\circ} \mathrm{C}\right)$, and then processed as above.

\subsubsection{Acid-labile phenolic acids}

To the freeze dried aqueous fractions, $\mathrm{HCl}(2 \mathrm{M} ; 3 \mathrm{ml})$ was added and the sample incubated at $95{ }^{\circ} \mathrm{C}$ for $30 \mathrm{~min}$ with intermittent mixing, then cooled to room temperature and extracted with EtOAc $(5 \mathrm{ml})$, shaken, vortexed and sonicated $(5 \mathrm{~min})$. Separation of the solvent layers by centrifugation (1800g; $5 \mathrm{~min} ; 18^{\circ} \mathrm{C}$ ), and then processed as above.

\subsection{Rapeseed pomace Soxhlet extraction}

For the Soxhlet (Gerhardt; Soxtherm SE 416) extraction both RSP from 2012 and 2014 (different breeds) were used. From now on extract from breed $A$, harvested in 2012, will be referred to as Ext. A, whereas extract from breed B, harvested in 2014, as Ext. B. First, both pomace samples were defatted as previously described (Sagdic et al., 2011; Wanasundara, Amarowicz, \& Shahidi, 1994) with some modifications. Ground pomace $(6.0 \mathrm{~g})$ was transferred into cellulose thimbles (Fioroni S.A X25 Extraction thimble $33 \times 80 \mathrm{~mm}$ ) for the Soxhlet extraction. The lipids were extracted with petroleum ether $(140 \mathrm{ml})$ as previously described (Liu, Wu, Pu, Li, \& Hu, 2012), in a shorter procedure. A 45 min petroleum ether extraction $\left(150^{\circ} \mathrm{C}\right)$ was followed by 4 intervals of evaporation (A), a $45 \mathrm{~min}$ rinsing cycle and 1 cycle of evaporation $B$. The defatted pomace filled thimbles were left to evaporate overnight in a fume hood, to remove any traces of solvent.

After $16 \mathrm{~h}$, a second extraction with an ethanol/water mixture (95:5, $140 \mathrm{ml}$ ) according to Sagdic et al. (2011) was undertaken, with minor modifications. A $45 \mathrm{~min}$ ethanol/water extraction $\left(240{ }^{\circ} \mathrm{C}\right.$ ) was followed by 4 intervals of evaporation (A), a $45 \mathrm{~min}$ rinsing cycle and one cycle of evaporation B. The total ethanol/ water extraction lasted three hours. The final evaporation (B) was aborted before complete dryness, to avoid charring of the extracts and to pool all of the extracts (of one RSP sample) into one pre-weight round bottom flasks $(150 \mathrm{ml})$. The extract was evaporated on a rotary evaporator (Büchi Rotavapor R-114), frozen and freeze dried (Edwards, Freeze Dryer Modulyo) to yield a powdered dry product.

\subsection{Folin-Ciocalteu-(FC) assay}

The FC assay was conducted according to Waterhouse (2003) with minor modifications. Gallic acid was prepared to give final concentrations from 0.01 to $0.20 \mathrm{mg} / \mathrm{ml}$. The extracts were dissolved (ethanol:water, 4:10) and further diluted in water. For the reaction to occur, test solutions $(25 \mu \mathrm{l})$ were mixed with distilled water $(200 \mu \mathrm{l})$ and FC reagent $(20 \mu \mathrm{l})(\mathrm{n}=3)$. After a short incubation time ( $3 \mathrm{~min}$ at room temperature), $20 \% \mathrm{Na}_{2} \mathrm{CO}_{3}$ solution $(25 \mu \mathrm{l})$ was added. After a second incubation $\left(37^{\circ} \mathrm{C} ; 30 \mathrm{~min}\right)$, the absorbance was read at $750 \mathrm{~nm}$ (BioTek $\mu$ Quant). SA, as most abundant phenolic, was analysed for comparison. The results are given as mg GAE/g dry extract $(C)$ by using the following formula, where $c$ equals the found concentration from the gallic acid calibration graph $(\mathrm{mg} / \mathrm{ml}), V$ is the used volume $(\mathrm{ml})$ of the extract and $M$ is the total mass $(\mathrm{g})$ of extract used in one well.

$$
C(m g G A E / g)=c(m g / m l) *\left(\frac{V(m l)}{M(g)}\right)
$$

\subsection{Chemical analysis of the extracts}

The extracts obtained from the Soxhlet extractions together with three fractions from the pomace (free, alkali- and acidlabile) were subjected to LC-MS/MS analysis, to determine their phytochemical profile. The EtOAc pomace extracts were dissolved in $0.5 \mathrm{ml}$ methanol. For the Soxhlet extracts, solutions with concentration of $1 \mathrm{mg} / \mathrm{ml}$ were prepared (95\% methanol/5\% deionized water). For analysis, each sample $(100 \mu \mathrm{l})$ was mixed with a standard $(400 \mu \mathrm{l})$ and then analysed as previously described by Russell et al. (Neacsu et al., 2013; Russell et al., 2011) on an Agilent 1100 HPLC system using a Zorbax Eclipse $5 \mu \mathrm{m}, 150 \mathrm{~mm} \times 4 \mathrm{~mm}$ column (both Agilent Technologies, Wokingham, UK).

\subsection{In vitro antioxidant activity}

\subsubsection{Ferric reducing/antioxidant power (Plasma)-(FRAP) assay}

The FRAP assay was performed according to Arya et al. (2013). To freshly prepared FRAP reagent, acetate buffer $(300 \mathrm{mM}$; $25 \mathrm{ml}$; pH 3.6), TPTZ (2.5 ml; $10 \mathrm{mM}$ in $40 \mathrm{mM} \mathrm{HCl})$ and $\mathrm{FeCl}_{3}{ }^{*} 6-$ $\mathrm{H}_{2} \mathrm{O}\left(2.5 \mathrm{ml}, 20 \mathrm{mM}\right.$ in $\left.\mathrm{dH}_{2} \mathrm{O}\right)$ were mixed and incubated $\left(37^{\circ} \mathrm{C}\right)$ until use. Trolox was prepared with concentrations ranging from 31.20 to $312.5 \mu \mathrm{g} / \mathrm{ml}$. The samples were prepared in ethanol:water (4:10) and diluted further with water to obtain the correct concentrations. Sample/blank/standard $(10 \mu \mathrm{l})$ were mixed with the FRAP reagent $(190 \mu \mathrm{l})$ and the absorbance at $593 \mathrm{~nm}$ (BioTek $\mu$ Quant) was read after incubation ( $30 \mathrm{~min}$, at room temperature, in the dark). SA, as the most abundant phenolic, was analysed for comparison. The results are expressed as Trolox equivalents (TE) and are given as $\mathrm{mg} \mathrm{TE} / \mathrm{g}$ dry extract $(C)$ by using the following formula, where $c$ is the concentration obtained from the Trolox calibration graph $(\mathrm{mg} / \mathrm{ml}), V$ is the volume $(\mathrm{ml})$ of extract and $M$ is the total mass $(\mathrm{g})$ of extract used in one well.

$C(m g T E / g)=c(m g / m l) *\left(\frac{V(m l)}{M(g)}\right)$

\subsubsection{2,2-Diphenyl-1-picrylhydrazyl- (DPPH) assay}

The radical scavenging activity of the samples was measured using the method by Sagdic et al. (2011) with minor modifications. Serial dilutions of all the extracts $(3.9-1000 \mu \mathrm{g} / \mathrm{ml})$ were prepared in methanol and $50 \mu \mathrm{l}$ mixed with freshly prepared DPPH solution ( $100 \mu \mathrm{l} ; 0.1 \mathrm{mM}$ in methanol), to yield final RSP extract concentrations between 1.3 and $333.3 \mu \mathrm{g} / \mathrm{ml}$. The plates were incubated in the dark ( $30 \mathrm{~min}$; at room temperature) and the absorbance was 
read at $517 \mathrm{~nm}$ (BioTek $\mu$ Quant). Furthermore, a serial dilution $(1.3-333.3 \mu \mathrm{g} / \mathrm{ml})$ of SA was analysed for comparison. The percentage of radicals present was calculated as below, where $A$ is the absorbance. The linear part of the obtained curve was used to determine the $\mathrm{IC}_{50}$ value, by plotting a linear graph and using the trend line for $\mathrm{IC}_{50}$ calculations.

$\%$ of radicals present $=\frac{\left(100 * A_{\text {sample }}\right)}{A_{\text {blank }}}$

\subsubsection{Oxygen radical absorbance capacity (ORAC) assay}

Samples were analysed according to Huang, Ou, HampschWoodill, Flanagan, and Prior (2002) with some modifications. From a Trolox stock solution, a series of solutions $(10-125 \mu \mathrm{M})$ were made in PBS $(75 \mathrm{mM}, \mathrm{pH} 7.4)$. To start the ORAC reaction, Trolox $(25 \mu \mathrm{l})$ and sodium fluorescein $(150 \mu \mathrm{l}$, $25 \mathrm{nM}$ ) were incubated $\left(30 \mathrm{~min}, 37^{\circ} \mathrm{C}\right)$. After the incubation, 2,2'-Azobis (2-amidnopropane) dihydrochloride (AAPH, $25 \mu \mathrm{l}$ ) was added and the reaction was monitored (over $2 \mathrm{~h}$ at $2 \mathrm{~min}$ intervals) at excitation and emission wavelengths of 485/20 and 525/20 nm, respectively (BioTek Synergy HT). RSP extract solutions were prepared $(1-50 \mu \mathrm{g} / \mathrm{ml})$ in PBS, giving final well concentrations of $0.125-6.25 \mu \mathrm{g} / \mathrm{ml}$. RSP extract samples were treated in the same way as the Trolox standard solutions described above. The Trolox standard series was run with all samples to determine $\mu \mathrm{mol}$ Trolox equivalents (TE)/g of dry extract $(C)$ from the net AUC calibration curve (see calculations below), where AUC is the area under the curve, $f_{x \min }$ the fluorescence measurement at the respective minute, $c$ is the concentration obtained from the Trolox calibration graph ( $\mu \mathrm{mol} / \mathrm{l}), V$ is the volume (L) of extract and $M$ is the total mass ( $g$ ) of extract used in one well.

AUC $=0.5+\frac{f_{2 \min }}{f_{0 \min }}+\frac{f_{4 \min }}{f_{0 \min }}+\frac{f_{6 \min }}{f_{0 \min }}+\ldots \frac{f_{118 \min }}{f_{0 \min }}+0.5\left(\frac{f_{120 \min }}{f_{0 \text { min }}}\right)$

net $A U C=A U C_{\text {sample }}-A U C_{\text {neg control }}$

$C(\mu \mathrm{molTE} / \mathrm{g})=c(\mu \mathrm{mol} / L) *\left(\frac{V(L)}{M(g)}\right)$

\subsection{Inhibition of supercoiled plasmid DNA strand breakage}

The inhibition of supercoiled plasmid DNA strand breakage was performed as previously described (de Camargo, Regitanod'Arce, Biasoto, \& Shahidi, 2014) with minor changes: $1 \mu \mathrm{l}$ pBR322 plasmid DNA $(50 \mu \mathrm{g} / \mathrm{ml})$ was incubated with $6 \mu \mathrm{l}$ PBS, $8 \mu \mathrm{l} \mathrm{AAPH}(10 \mathrm{mM})$ and $8 \mu \mathrm{l} \mathrm{RSP}$ extract $(60-10 \mu \mathrm{g} / \mathrm{ml})$ or $8 \mu \mathrm{l}$ SA $(60.00-0.29 \mu \mathrm{g} / \mathrm{ml})$ for comparison. The total volume of the reaction mixture is $23 \mu$ l, giving final RSP extract concentrations between $20.9-3.5 \mu \mathrm{g} / \mathrm{ml}$, total SA concentrations between $20.9 \mathrm{~m}$ and 0.1 and a final AAPH concentration of $3.5 \mathrm{mM}$. AAPH and/or extracts/SA were substituted with PBS for controls. The mixture was vortexed, centrifuged briefly (10000rcf, Eppendorf centrifuge $5415 \mathrm{D})$ and incubated in the dark $\left(37^{\circ} \mathrm{C}, 60 \mathrm{~min}\right)$.

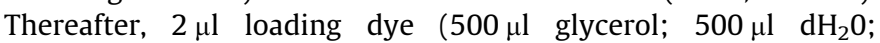
$5 \mathrm{mg}$ bromophenol blue) were added, the sample vortexed and loaded $(10 \mu \mathrm{l})$ onto a $0.7 \%$ agarose gel, prepared with TAE buffer ( $40 \mathrm{mM}$ Tris acetate, $1 \mathrm{mM}$ EDTA), stained with gel red dye $(0.01 \%)$ and electrophoresed (70 min; $80 \mathrm{~V}$ (Life Technologies Horizon 58 gel tank and Thermo EC 105 power pack) in TAE buffer. The gels were visualized and photographed using Peqlab Fusion FX7 (Fusion 15.11 software) under UV-light. ImageJ software was used to analyse the band intensity. Inhibition of DNA strand breakage (\%) was calculated using the following formula:
Inhibition of DNA strand breakage (\%)

DNA content with the oxidative radical and extract (band intensity) $=\frac{\text { DNA content without the oxidative radical (band intensity) }}{}$ $* 100 \%$

\subsection{Statistics}

Data are shown as mean \pm standard deviation and all experiments were run at least in triplicate. Statistical analysis was performed using Prism6 (GraphPad Software, San Diego, CA, USA), depending on the experiment either using unpaired $t$-test or multiple $t$-test without correction for multiple comparison. Significant differences are labelled accordingly (ns- not significant, $\mathrm{p}<0.05^{*}$, $\left.\mathrm{p}<0.01^{* *}, \mathrm{p}<0.001^{* * *}, \mathrm{p}<0.0001^{* * * *}\right)$.

\section{Results and discussion}

\subsection{LC-MS/MS analysis of rapeseed pomace}

The aim of applying the different ethyl acetate extractions was to analyse which secondary metabolites would be available if RSP would be used for human consumption. Free phenolic acids are easily absorbed in the small intestine (Russell, Scobbie, Labat, \& Duthie, 2009) and these compounds were measured by simple solvent extraction into ethyl acetate (Table 1, Supplementary Data 1). However, the majority are found esterified to other plant components, including sugars and complex carbohydrates. When bound to cell wall components, such as polysaccharides and lignin, they are unlikely to be absorbed in the small intestine and are only be available after microbial release and metabolism in the colon (Kroon, Faulds, Ryden, Robertson, \& Williamson, 1997). Bound metabolites were measured by alkali and acid extraction and although this does not allow the determination of the conjugate, it allows for a more accurate quantification. As expected, most metabolites were obtained following alkali and/or acid extractions, e.g. approximately $80 \%$ of sinapic acid was extracted after alkali treatment, while most of the kaempferol (99.8\%) was obtained after acid treatment (Table 1, Supplementary Data 1).

Similar free phenolic acids were found previously (Krygier, Sosulski, \& Hogge, 1982), when analysing 3 different defatted rapeseed cultivars (flour), showing the presence of p-hydroxybenzoic, vanillic, gentisic, protocatechuic, syringic, p-coumaric, ferulic, sinapic, and chlorogenic acid at different concentrations depending on the cultivar, SA being the most abundant in all 3 samples. In general, few studies have been carried out on the accessible secondary metabolites after ethyl acetate extraction of rapeseed pomace/ meal, and most times the solvents of choice are methanol, ethanol, water or mixtures of these (Chandrasekara, Rasek, John, Chandrasekara, \& Shahidi, 2016; Thiyam et al., 2004).

However, compared to the solid-liquid ethyl acetate extraction, Soxhlet extraction methods are simpler, faster and amenable to automation and large scale. Therefore, in this study we employed an automated Soxhlet extraction method to extract secondary metabolites after an initial defatting step using petroleum ether. The latter step was essential since it removed all excessive oil from the RSP. After ethanol/water (95:5) extraction, subsequent drying afforded a dry solid extract, which was easier to handle than extracts obtained without the petroleum ether extraction.

\subsection{Rapeseed pomace Soxhlet extracted samples}

Soxhlet extraction was performed, to understand which secondary metabolites are easily extracted with an environmentally safer ethanol/water (95:5) mixture, for further potential applications. The ground rapeseed pomace from both harvests were 
Table 1

Concentrations ( $\mathrm{mg} / \mathrm{kg}$ pomace) of the most abundant secondary metabolites found in both RSP samples after free, alkali-labile and acid-labile extractions.

\begin{tabular}{|c|c|c|c|c|}
\hline Secondary metabolite & Extraction & RSP A (mg/kg pomace) & RSP B (mg/kg pomace) & Significant difference \\
\hline \multirow{3}{*}{ Sinapic acid } & Free & $224.24 \pm 3.58$ & $161.40 \pm 25.55$ & ${ }^{*}$ \\
\hline & Alkali-labile & $917.650 \pm 43.78$ & $1072.14 \pm 32.38$ & $* * *$ \\
\hline & Acid-labile & $11.31 \pm 1.38$ & $10.54 \pm 1.25$ & \\
\hline \multirow[t]{3}{*}{ Indol-3-pyruvic acid } & Free & $3.04 \pm 0.39$ & $53.54 \pm 87.11$ & \\
\hline & Alkali-labile & $76.17 \pm 131.93$ & $197.68 \pm 37.96$ & \\
\hline & ACID-labile & $381.40 \pm 71.97$ & $223.58 \pm 123.48$ & \\
\hline \multirow{3}{*}{ Kaempferol } & free & $0.19 \pm 0.01$ & $0.75 \pm 0.53$ & \\
\hline & Alkali-labile & $0.11 \pm 0.01$ & $0.20 \pm 0.01$ & $* * *$ \\
\hline & Acid-labile & $141.30 \pm 6.77$ & $152.62 \pm 5.54$ & \\
\hline \multirow[t]{3}{*}{ Ferulic acid } & Free & $12.25 \pm 0.30$ & $9.570 \pm 1.63$ & ${ }^{*}$ \\
\hline & Alkali-labile & $64.55 \pm 39.37$ & $38.65 \pm 2.07$ & \\
\hline & Acid-labile & $1.53 \pm 0.17$ & $1.23 \pm 0.06$ & ${ }^{*}$ \\
\hline \multirow{3}{*}{ Protocatechuic acid } & Free & $2.52 \pm 0.04$ & $5.40 \pm 0.81$ & ** \\
\hline & Alkali-labile & $16.54 \pm 3.76$ & $24.12 \pm 1.20$ & * \\
\hline & Acid-labile & $17.14 \pm 0.53$ & $17.42 \pm 0.94$ & \\
\hline
\end{tabular}

* Further metabolites can be found in Error! Reference source not found., statistical analysis was performed using multiple t-tests without correction for multiple comparison in Graph Pad Prism6 (statistical significance with alpha $=5.000 \%, \mathrm{p}<0.05^{*}, \mathrm{p}<0.01^{* *}, \mathrm{p}<0.001^{* * *}$ ).

extracted using automated Soxhlet (SOX) extraction and a solvent mixture of ethanol/water (95:5) after petroleum ether defatting. Extract yields after ethanol/water extraction and drying were found to be about $8 \%$ for both harvests. An ethanol/water mixture was chosen as extraction solvent, since it is perceived as a 'green' solvent system when compared with methanol or other organic solvent mixtures. In addition, it was previously reported that ethanol/water mixture (75 and $95 \mathrm{wt} \%$ ethanol) is effective for phenolic extraction (Sun, Wu, Wang, \& Zhang, 2015). Soxhlet extraction with this ratio of ethanol/water together with a petroleum ether defatting step, has not been reported before, thus making yields comparison difficult. However, a previous report, where a 95:5 mixture of ethanol/water was used on RSP in a water bath (30 min at $80^{\circ} \mathrm{C}$; reflux system), showed almost double the extraction yields (14-15\%) (Hassas-Roudsari, Chang, Pegg, \& Tyler, 2009) which could be due to the fat content, since a defatting step was not included in their extraction methodology. More recently, Chandrasekara et al. (2016) reported yields around 10\% when using defatted rapeseed seeds in four different extraction techniques with $80 \%$ ethanol as solvent. Their extraction yield is much closer to what was obtained in our study $(\sim 8 \%)$.

\subsection{Folin-Ciocalteu (FC) assay}

The RSP extracts for both harvest years were subjected to the Folin-Ciocalteu (FC) assay, to determine their reducing capacity. The results showed a mean of $51.9 \pm 1.7$ and $55.8 \pm 1.0 \mathrm{mg} \mathrm{GAE} / \mathrm{g}$ dry weight of extract for Ext. A and B, respectively, thus confirming the presence of phenolics in both Soxhlet extracts (Supplementary Data 2). Statistical analysis indicated the differences between the harvest years to be insignificant.

It is worth mentioning that these results from the FC assay are in agreement with previous results (Cvjetko, Lepojević, Zeković, Vidović, \& Milošević, 2009). Cvejetko et al. reported the following: 51.7 (80\% ethanol), 54.0 (60\% ethanol), 55.7 (70\% methanol) $\mathrm{mg}$ $\mathrm{GAE} / \mathrm{g}$ using defatted rapeseed pomace/meal and ultrasonic assisted extraction at $45{ }^{\circ} \mathrm{C}$ for $40 \mathrm{~min}$. Although data on the content of total polyphenols in the rapeseed oil itself is not readily available, it is however interesting to note that in one publication (Kostadinovic-Velickovska \& Mitrev, 2013) it was shown that cold pressed rapeseed oil had polyphenol equivalent to $1.56 \mathrm{mgGAE} / \mathrm{g}$. This implies that extract from our RSP has about 35 times more polyphenols than the oil itself.

Although the FC method is widely applied to determine the reducing capacity of samples, because it is fast and easy to use, it has limitations. The resulting colour change, from yellow to blue, is due to the oxidation of phenolics, to form molybdenum oxide. The intensity of the colour change depends on the concentration of phenolics present. Thus, the assay actually measures the samples reducing capacity, which is not reflected in its common name "total phenolic assay". This oxidation reaction can also be caused by non-phenolics, such as aromatic amines, sugars and ascorbic acid (Huang, Ou, Prior, \& Rior, 2005). Therefore, LC-MS/MS analysis was undertaken to determine the presence of phenolics, indoles, amines, flavonoids and coumarins in the same way as was done for the free and bound fractions of the pomace sample above.

\subsection{LC-MS/MS analysis of Soxhlet extracts}

In addition to the reducing capacity shown by the FC assay, LC-MS/MS analysis was able to show the presence of secondary metabolites, such as benzoic acids, benzaldehydes, amines, indoles, flavonoids and coumarins, all of which are presented in Supplementary Data 3. The most abundant compound found, was SA (Table 2). This agrees with the results obtained from the pomace analysis (free, alkali- and acid-labile) discussed above (Table 1, Supplementary Data 1), as well as with previously reported results on the composition of rapeseed extracts (Jun, Wiesenborn, \& Kim, 2014; Szydłowska-Czerniak, Trokowski, Karlovits, \& Szłyk, 2010). Other phenolics at high concentrations were ferulic acid (Ext. A: $226.54 \pm 8.37 \mathrm{mg} / \mathrm{g}$ extract, Ext. B: $182.70 \pm 9.82 \mathrm{mg} / \mathrm{g}$ extract), caffeic acid (Ext. A: $97.28 \pm 7.26$ $\mathrm{mg} / \mathrm{g}$ extract, 2014: $110.83 \pm 9.57 \mathrm{mg} / \mathrm{g}$ extract), syringic acid (Ext. A: $44.82 \pm 2.45 \mathrm{mg} / \mathrm{g}$ extract, Ext. B: $224.23 \pm 16.54 \mathrm{mg} / \mathrm{g}$ extract) and 4-hydroxyphenylpyruvic acid (Ext. A: $172.74 \pm 43.61$ $\mathrm{mg} / \mathrm{g}$ extract, Ext. B: $149.77 \pm 39.56 \mathrm{mg} / \mathrm{g}$ extract), some of which have been found in rapeseed extracts before (Jun et al., 2014) (Table 2). For example, in a $80 \%$ methanol extract of canola seed (rapeseed), by Jun et al. (2014), $41.4 \mathrm{mg} / \mathrm{g}$ trans-sinapic acids and $0.1 \mathrm{mg} / \mathrm{g}$ caffeic acid were found, as well as $10.4 \mathrm{mg} / \mathrm{g}$ gallic acid, $4.8 \mathrm{mg} / \mathrm{g}$ protocatechuic acid and $2.5 \mathrm{mg} / \mathrm{g}$ chlorogenic acid. Both gallic acid and chlorogenic acid were not detected in our samples (Table 2). However, protocatechuic acid was found as well (Supplementary Data 3, Table 2).

It is interesting to note that higher levels of the polyamine spermidine (a triamine) were found in the extracts than in the total fraction of the pomace (Supplementary Data 3). Cyclic spermidine conjugates have previously been found in rapeseed seeds, mainly distributed in the hypocotyl and radicle (Fang et al., 2012). Cinnamic acid is another metabolite which is present at higher concentrations (double) in the Soxhlet extracts than expected from the pomace analysis, as shown in Supplementary Data 3. This 
Table 2

Secondary metabolites distribution obtained for Ext. A and Ext. B, showing only metabolites that were detected.

\begin{tabular}{|c|c|c|c|c|}
\hline Secondary metabolites & & Ext. A (mg/kg RSP extract) & Ext. B (mg/kg RSP extract) & Significant difference \\
\hline \multirow[t]{6}{*}{ Benzoic Acids } & Salicylic acid & $11.47 \pm 0.60$ & $14.99 \pm 2.90$ & \\
\hline & p-Hydroxybenzoic acid & $48.97 \pm 8.15$ & $74.89 \pm 30.78$ & $* *$ \\
\hline & Protocatechuic acid & $32.27 \pm 23.50$ & $72.59 \pm 34.11$ & $* * * *$ \\
\hline & p-Anisic acid & $0.00 \pm 15.40$ & $28.11 \pm 17.06$ & $* * *$ \\
\hline & Vanillic acid & $41.85 \pm 0.51$ & $44.72 \pm 16.80$ & \\
\hline & Syringic acid & $44.82 \pm 94.11$ & $224.23 \pm 122.92$ & $* * * *$ \\
\hline \multirow[t]{3}{*}{ Benzaldehydes } & Protocatechualdehyde & $54.46 \pm 2.99$ & $48.83 \pm 28.65$ & \\
\hline & Vanillin & $17.26 \pm 2.35$ & $15.08 \pm 8.98$ & \\
\hline & Syringin & $64.30 \pm 18.57$ & $33.58 \pm 14.98$ & $* * *$ \\
\hline \multirow[t]{5}{*}{ Cinnamic Acids } & Cinnamic acid & $107.94 \pm 25.13$ & $69.59 \pm 4.08$ & $* *$ \\
\hline & p-Coumaric acid & $46.97 \pm 10.21$ & $32.10 \pm 10.36$ & $* *$ \\
\hline & Caffeic acid & $97.28 \pm 7.37$ & $110.82 \pm 36.86$ & \\
\hline & Ferulic acid & $226.54 \pm 34.62$ & $182.70 \pm 31.00$ & $*$ \\
\hline & Sinapic acid & $7496.72 \pm 1737.73$ & $4896.91 \pm 239.01$ & $* * * *$ \\
\hline Phenylpyruvic acids & 4-Hydroxyphenylpyruvic acid & $172.74 \pm 19.09$ & $149.77 \pm 26.35$ & \\
\hline Phenolics others & 4-Hydroxyl 3-methoxyl benzyl alcohol & $0.00 \pm 0.00$ & $0.76 \pm 1.32$ & \\
\hline \multirow[t]{2}{*}{ Indoles } & Indole-3-carboxylic acid & $17.36 \pm 3.48$ & $11.78 \pm 3.97$ & $* * *$ \\
\hline & Indole-3-pyruvic acid & $480.81 \pm 134.06$ & $336.05 \pm 184.15$ & \\
\hline \multirow{2}{*}{ Amines } & Spermine & $2.68 \pm 0.61$ & $1.82 \pm 0.05$ & $\cdot$ \\
\hline & Spermidine & $524.93 \pm 66.30$ & $433.56 \pm 58.87$ & \\
\hline \multicolumn{5}{|l|}{ Flavanoids/Coumarins } \\
\hline & Tangeretin & $1.09 \pm 0.14$ & $0.93 \pm 0.09$ & \\
\hline & Naringenin & $3.53 \pm 0.79$ & $2.58 \pm 1.57$ & ${ }^{* *}$ \\
\hline & Kaempferol & $123.69 \pm 31.10$ & $22.32 \pm 2.42$ & \\
\hline & Quercetin-3-Glucoside & $0.00 \pm 3.62$ & $6.72 \pm 4.07$ & $* * *$ \\
\hline & Phloridzin & $0.00 \pm 1.05$ & $2.09 \pm 1.30$ & $* * *$ \\
\hline & Luteolin & $18.75 \pm 13.76$ & $44.66 \pm 22.24$ & $* * *$ \\
\hline & Isorhamnetin & $27.89 \pm 7.53$ & $7.85 \pm 1.53$ & \\
\hline & Apigenin & $4.78 \pm 1.60$ & $2.31 \pm 0.32$ & $* *$ \\
\hline & BDCA & $26.51 \pm 18.29$ & $29.93 \pm 6.21$ & \\
\hline
\end{tabular}

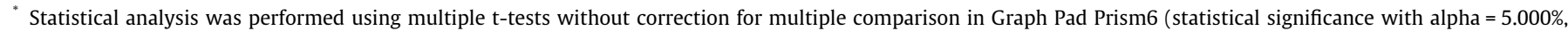
$\mathrm{p}<0.05^{*}, \mathrm{p}<0.01^{* *}, \mathrm{p}<0.001^{* * *}, \mathrm{p}<0.0001^{* * * * *}$ ).

might be due to the difference in extraction solvents used (ethyl acetate and ethanol/water).

All secondary metabolites found in the Soxhlet extracts and their respective weights (mg/g RSP extract) are shown in Supplementary Data 3, together with the values from the total (free, alkali- and acid-labile fractions) and free acid fraction (free fraction) obtained from the pomace. In general, Ext. A appears to show higher levels of secondary metabolites than Ext. B, which is surprising, considering they both showed similar results in the reducing capacity assay (FC assay (Supplementary Data 2)). For most compounds, ethyl acetate extraction (FA) was not able to extract the total amount of metabolites found in the pomace $(\mathrm{FA}+\mathrm{ALK}+\mathrm{ACD})$

When comparing the results obtained from both extracts, it is noticeable that, in Ext. A, cinnamic acids concentrations are higher, whereas, in Ext. B benzoic acids were the most abundant (Supplementary Data 3, Table 2). In general, the production of different secondary metabolites can be influenced by environmental factors, such as high UV-light, pathogen attack, wounding and temperature or low nutrients, such as phosphate, nitrogen or iron (Dixon \& Paiva, 1995). Moreover the two different breeds grown and harvested in two different years (2012 and 2014), may impact on the secondary metabolite composition, as well as other factors, such as storage time and environmental conditions of the seeds and the pomace at the provider end and storage time in the laboratory. Although a difference in secondary metabolite composition was found, their reducing capacity (FC assay) was found not to be significantly different in this study (Supplementary Data 2).

Phenolics found in the RSP extracts, such as SA and ferulic acid, are well known antioxidants while exhibiting interesting chemical and biological activities (Haque, Javed, Azimullah, Abul Khair, \& Ojha, 2015; Kim et al., 2010; Kwon et al., 2012). SA for example had shown DPPH radical scavenging (Thiyam, Stöckmann, Zum Felde, \& Schwarz, 2006), superoxide $\mathrm{O}_{2}^{-}$, hydroxyl ('OH), nitro oxide ( $\mathrm{NO})$, and peroxynitrite $\left(\mathrm{ONOO}^{-}\right)$scavenging properties, as well as suppression of lipid peroxidation (Zou, Kim, Kim, Choi, \& Chung, 2002). In other studies, SA and ferulic acid, for example, were found to show health promoting effects in different model organisms (Haque et al., 2015; Kim et al., 2010; Kwon et al. 2012). However, little information on the antioxidant activity is available for other phytochemicals, such as syringic acid and 4hydroxyphenylpyruvic acid.

\subsection{Antioxidant analysis of RSP ethanol extracts}

Depending on the chemical reactions involved, in vitro antioxidant assays can be based on hydrogen atom transfer (HAT) or electron transfer (ET). One HAT based (Oxygen Radical Absorbance Capacity-ORAC) and two ET based (2,2-Diphenyl-1picrylhydrazyl- and Ferric Reducing/Antioxidant Power (Plasma)assay) assays were applied to analyse RSP extracts' antioxidant activity. Those assays look at the activity of extracts at different pH's (FC-basic, FRAP-acidic), their ability to scavenge stable nitrogen radicals (DPPH) and to protect a fluorescence probe from decay after peroxyl radical production by AAPH over time (ORAC) (Huang et al., 2005).

\subsection{1. .FRAP assay}

The FRAP assay determines the capacity of the extracts to reduce the ferric-tripyridyltriazine complex to the ferroustripyridyltriazine complex by electron transfer reaction. The reduction leads to a colour change of the solution, measured at $593 \mathrm{~nm}$ (Huang et al., 2005).

The results here showed (Fig. 2A) that Ext. B $(172.43 \pm 2.18 \mathrm{mg}$ TE/g dry weight RSP) exhibited significantly better $(p=0.027)$ ferric reducing antioxidant power than Ext. A $(163.45 \pm 2.19 \mathrm{mg} \mathrm{TE} / \mathrm{g}$ dry weight RSP). 


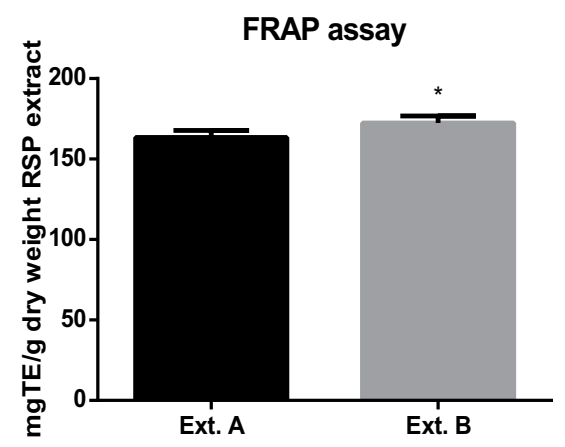

A

\section{ORAC assay}

Ext. A

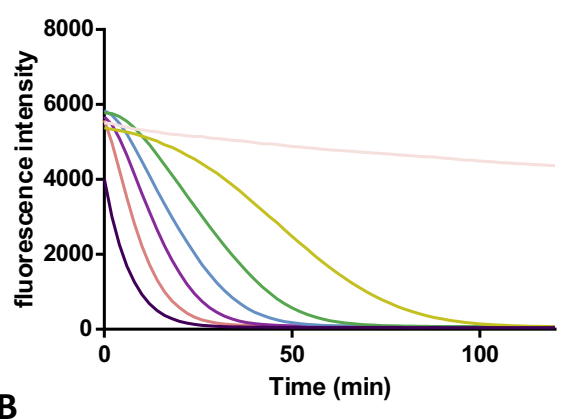

Ext. B

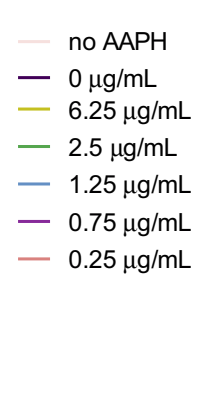

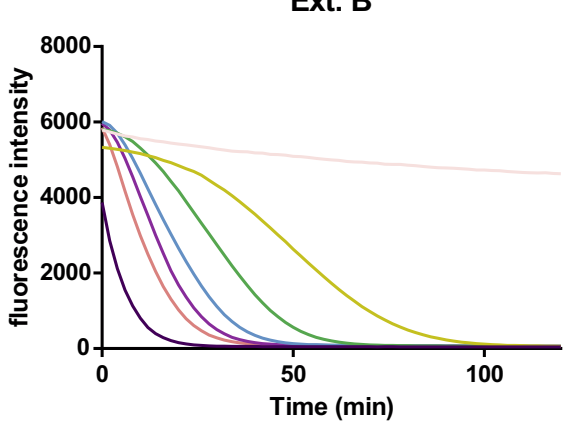

no AAPH

$-0 \mu \mathrm{g} / \mathrm{mL}$

$-6.25 \mu \mathrm{g} / \mathrm{mL}$

$-2.5 \mu \mathrm{g} / \mathrm{mL}$

$-1.25 \mu \mathrm{g} / \mathrm{mL}$

$-0.75 \mu \mathrm{g} / \mathrm{mL}$

$-0.25 \mu \mathrm{g} / \mathrm{mL}$

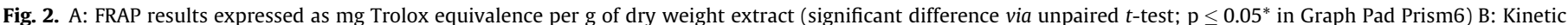

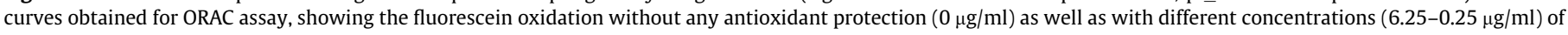
both extracts (Ext. A and Ext. B), compared to the (no AAPH) control.

It is interesting to note that as in the FC assay, the extract with the highest total amounts of secondary metabolites and highest concentrations of SA (Ext. A) (Table 2) did not demonstrate the best ferric reducing activity when compared with Ext. B, suggesting that $\mathrm{SA}$ is not the only compound in the extract responsible for the antioxidant activity. This was confirmed when the SA concentration $(0.24 \mu \mathrm{g} / \mathrm{ml}$ in Ext. B) present in the extract was used alone in the FRAP/FC assay (Supplementary Data 4).

For example, a final well concentration of $50 \mu \mathrm{g} / \mathrm{ml}$ Ext. B extract gave absorbance measurements of $1.06 \pm 0.006$. However, at $0.24 \mu \mathrm{g} / \mathrm{ml} \mathrm{SA}$ (concentration of SA present in $50 \mu \mathrm{g} / \mathrm{ml}$ Ext. B) only an absorbance reading of 0.156 was observed (Supplementary Data 4A).

A similar trend was observed in the FC assay. For example a concentration of $1 \mathrm{mg} / \mathrm{ml}$ of Ext. B in the FC assay gave an absorbance of $0.462 \pm 0.013$ while SA at $0.0049 \mathrm{mg} / \mathrm{ml}$ (concentration found in $1 \mathrm{mg} / \mathrm{ml}$ extract) gave an absorbance of $0.096 \pm 0.001$ (Supplementary Data 4B).

In both FRAP and FC assays, the amount of SA responsible for activity is less than $10 \%$ of the absorbance change/activity. Potentially other compounds present in high concentrations, such as phydroxybenzoic acid, syringic acid, protocatechnic acid, caffeic acid or ferulic acid, may have more impact on the in vitro antioxidant activity found for the Soxhlet extracts. Furthermore, the antioxidant activity found in the extracts could be caused by compounds that were not analysed but are known to be present in rapeseed plants, such as glucosinolates, tocols, phytosterols and phospholipids (Szydłowska-Czerniak, 2013). In addition, potential synergic effects of the different secondary metabolites could contribute to the enhanced antioxidant property of the RSP extracts (Wagner, 2011).
When comparing results from the FRAP assay with the methanol extracts of waste and by-products of other plants (Wijngaard et al., 2009), the RSP extracts seem very promising, as they showed activity 10 times higher than, for example, kiwifruit, pink grapefruit and apple pomace extracts. Up to 20 times higher results were obtained when compared to vegetable by-products, such as white cabbage cut-offs, cauliflower cut-offs and broccoli stems (methanol extracts) (Wijngaard et al., 2009). In a paper by SzydłowskaCzerniak, Bartkowiak-Broda, Karlović, Karlovits, and Szłyk (2011) it was shown that the FRAP and DPPH activity together, as well as the concentrations of erucic acid and total glucosinolates, were dependent on the breed/variety and their origin. In our study, the origin for both samples was the same, however the breed and the year of harvest were different for both samples and either could have contributed to the difference in the FRAP activity.

\subsubsection{DPPH assay}

The radical scavenging activity of RSP extracts was carried out by the DPPH assay (Supplementary Data $5 \mathrm{~B}$ ) and the $\mathrm{IC}_{50}$ values of the RSP extracts were determined. The lower the $\mathrm{IC}_{50}$ value, the stronger the radical scavenging activity of the sample. Both extracts gave similar, not significantly different $\mathrm{IC}_{50}$ values, $56.19 \pm 1.90 \mu \mathrm{g} / \mathrm{ml}$ for Ext. B and $59.84 \pm 1.53 \mu \mathrm{g} / \mathrm{ml}$ for Ext. A (Supplementary Data 5A).

In a paper published by Hassas-Roudsari et al. (2009) the free radical scavenging activity of four RSP extracts obtained by using different extraction methods (with no defatting step), showed weaker radical scavenging activity ( $\mathrm{IC}_{50}$ values between 110 and $330 \mu \mathrm{g} / \mathrm{ml}$ (read from the graph (Hassas-Roudsari et al., 2009)), compared to defatted extracts $\left(\mathrm{IC}_{50}\right.$ value $\sim 60 \mu \mathrm{g} / \mathrm{ml}$ (Supplementary Data 5) in this study. This could be due to the oils still present 
in the extracts, which increased the weight, while not contributing to the radical scavenging activity of the extracts. Even lower scavenging activities were found in a paper by Jun et al. (2014) where $80 \%$ methanol extracts from 4 different rapeseed varieties gave $\mathrm{IC}_{50}$ values at around $700 \mu \mathrm{g} / \mathrm{ml}$. However, Cvjetko et al. (2009) showed slightly better results than our study with the following lower $\mathrm{IC}_{50}$ values: methanol extraction $\mathrm{IC}_{50}=9 \mu \mathrm{g} / \mathrm{ml}, 60 \%$ ethanol extraction $\mathrm{IC}_{50}=13 \mu \mathrm{g} / \mathrm{ml}$ and $80 \%$ ethanol extraction $\mathrm{IC}_{50}=15 \mu \mathrm{g} / \mathrm{ml}$.

To compare the radical scavenging activity of the rapeseed pomace extracts with pure SA, the obtained SA activity curve is shown in Supplementary Data 6B. When analysing $333.33 \mu \mathrm{g} / \mathrm{ml}$ RSP extract in the DPPH assay the plateau of potential radical scavenging is reached (Supplementary Data 6A, marked with red box). The concentration of SA in this sample is 2.50 and $1.63 \mu \mathrm{g} / \mathrm{ml}$ for Ext. A and Ext. B respectively. At these SA concentrations, 72.0 and $80.2 \%$ of radicals are still present respectively. This confirms, as in the case of the FC and FRAP assay, that SA, although the most abundant phenolic acid in the extract, is not the sole contributor of the antioxidant activity from the extracts.

\subsubsection{ORAC assay}

The ORAC analysis gave a mean value of $2825.2 \pm 50.48$ and $2607.4 \pm 122.5 \mu \mathrm{mol} \mathrm{TE} / \mathrm{g}$ dry weight (at $2.5 \mu \mathrm{g} / \mathrm{ml}$ ) for Ext. A and Ext. B respectively, showing no significant difference between the breeds and harvest years (Supplementary Data 7). Both extracts inhibit and/or delay the probes (fluorescein) oxidation caused by oxidative stress inducer AAPH. The latter produces a peroxyl free radical upon thermal decomposition which is commonly found in the body, making this reaction more relevant to biological systems (Isa et al., 2012).

Fig. 2B shows the kinetic curves obtained for different concentrations $(6.25,2.5,1.25,0.75,0.25 \mu \mathrm{g} / \mathrm{ml})$, showing the protection properties of both RSP extracts over time, compared to the $0 \mu \mathrm{g} /$ $\mathrm{ml}$ control.

Even at very low concentrations of the extract $(0.25 \mu \mathrm{g} / \mathrm{ml})$ partial protection of the fluorescence probe, fluorescein, from the damaged caused by AAPH, is observed (Fig. 2B). Our ORAC results were significantly higher than those obtained by Chandrasekara et al. (2016) who applied four extraction methods with ethanol (reflux, homogenization, cold extraction and sonication). It is interesting to note that they used $80 \%$ ethanol, with an extraction temperature below $60^{\circ} \mathrm{C}$. The latter conditions together with the origin of the rapeseed, could have contributed to their lower ORAC activity.

\subsection{Inhibition of supercoiled plasmid DNA strand breakage by RSP extracts}

As previously demonstrated in the ORAC assay above, AAPH is able to decrease the fluorescence intensity of the used fluorescence probe, caused by radical generation. AAPH is also able to cause oxidative DNA strand breakage in pBR322 plasmid (Wei et al., 2006), from the supercoiled to both an opened circular and linear form of the plasmid DNA (Fig. 3). Previous research had shown that certain natural compounds, such as green tea polyphenols (Wei et al., 2006), Terminalia arjuna bark extracts (Phani Kumar et al.,

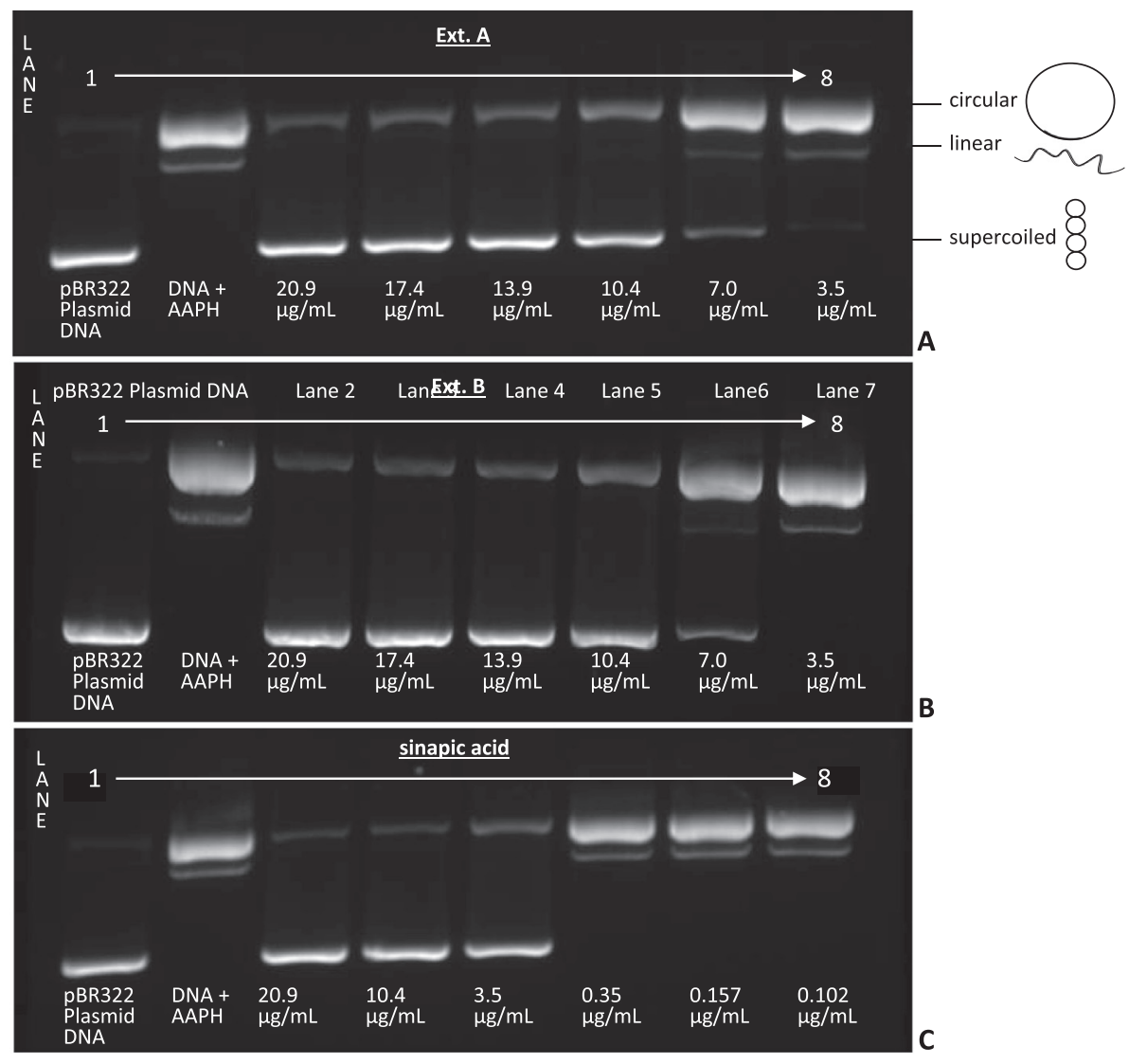

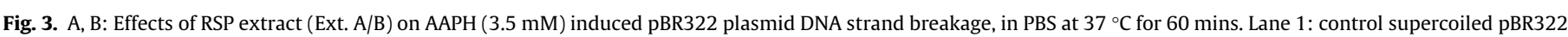

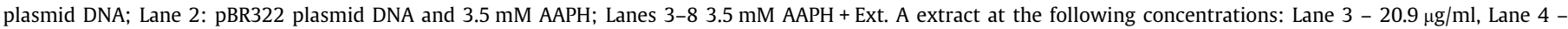

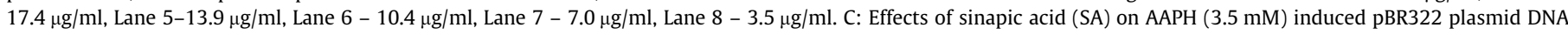

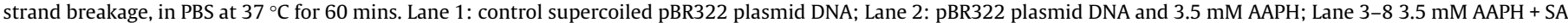

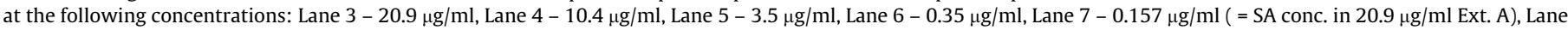
$8-0.102 \mu \mathrm{g} / \mathrm{ml}$ (=SA conc. in $20.9 \mu \mathrm{g} / \mathrm{ml}$ Ext. B). 
2013) and phenolic extracts from Sphallerocarpus gracilis seeds (Gao, Tian, Zhou, Zhang, \& Lu, 2014) are able to prevent plasmid DNA strand breakage at certain concentrations.

Similar observations were made, for the first time, with the Soxhlet RSP extracts in the present study. RSP extracts with concentrations between 20.9 and $13.9 \mu \mathrm{g} / \mathrm{ml}$ showed almost complete protection from the AAPH induced oxidative stress (Fig. 3A and B). Lower extract concentrations, such as 10.4 and $7.0 \mu \mathrm{g} / \mathrm{ml}$, still showed partial DNA protection. No visible DNA protection was observed at $3.5 \mu \mathrm{g} / \mathrm{ml}$.

In order to investigate whether the presence of the most abundant phenolic compound, SA, in the RSP extract, is the main contributor for DNA protection, the respective concentrations found in $20.9 \mu \mathrm{g} / \mathrm{ml}$ of both RSP extracts (Ext. A: 0.157 and Ext. B: $0.102 \mu \mathrm{g} / \mathrm{ml}$ ) were tested. Furthermore, concentrations of SA between 0.35 and $20.9 \mu \mathrm{g} / \mathrm{ml}$ were assessed.

While the three highest test concentrations (20.9, 10.4 and $3.5 \mu \mathrm{g} / \mathrm{ml}$ ) of SA showed very good protective properties, lower concentrations, such as $0.35 \mu \mathrm{g} / \mathrm{ml}$, and the relevant extract concentrations ( 0.157 and $0.102 \mu \mathrm{g} / \mathrm{ml}$ in $20.9 \mu \mathrm{g} / \mathrm{ml}$ extract) showed little or no visible protection respectively (Fig. $3 \mathrm{C}$ ).

The above results confirm that although SA is the most abundant compound present in the extracts, it is not the sole contributor to the DNA protective activity of the RSP extract. The protective effect may be due to other metabolites found in the extracts (Table 2, Supplementary Data) which could act in synergistic fashion. In addition, the protection could be caused by other compounds which were not analysed throughout this study as mentioned above for the FC, FRAP and DPPH assay.

\section{Conclusion}

The results obtained in this study showed that RSP, a by-/waste-product of rapeseed oil production, contains many secondary metabolites as seen in the free, alkali- and acid-labile extractions analysed by LC-MS/MS (Table 1, Supplementary Data $1)$. This method of analysis allows us to determine which secondary metabolites are freely available and bound, giving an indication about when and where they may be released and subsequently taken up in the digestive system. However, for a commercially exploitable extraction process an automated Soxhlet extraction was employed using petroleum ether to defat the pomace first, followed by ethanol/water (95:5) extraction. The Soxhlet extraction was successful in extracting secondary metabolites, such as derivatives of benzoic acids, benzaldehydes, amines, indoles, flavonoids and coumarins, in a timely and efficient manner showing strong antioxidant activity. LC-MS/MS analysis showed high abundance of SA as previously reported by others (Jun et al., 2014; Szydłowska-Czerniak et al., 2010). The different harvest year/breeds appeared to have some impact on certain metabolites, e.g. SA, syringic acid, protocatechuic acid and luteolin (Table 2, Supplementary Data 3). However, this does not affect the overall antioxidant activity, as no significant differences were observed for FC, DPPH or ORAC activity. Only the FRAP assay showed minor significant difference $(p=0.027)$, which could be caused by the different breeds and/or harvest years, the same is true for the varying secondary metabolite distributions in both samples.

We were also able to show that the antioxidant/radical scavenging properties exhibited by the RSP extracts were not caused solely by the most abundant secondary metabolite; SA. The same observations were obtained in the DNA protection assay. Therefore, it can be concluded that overall activity of the extract is likely due to the synergistic effect of many compounds present in the extract.
In general, the promising results obtained in this study warrant a more detailed investigation into the potential revalorisation of RSP. The by-product of the oil-extracting process, currently used as fodder in animal nutrition, might have the potential to be implemented as a food additive or dietary supplement with possible health promoting properties.

\section{Conflicts of interest}

There are no conflicts of interest to declare.

\section{Acknowledgements}

We would like to acknowledge Macintosh of Glendaveny for providing the rapeseed pomace samples for this study, Gary Duncan for the LC-MS/MS analysis and financial support from Tenovus Scotland - Grampian.

\section{Appendix A. Supplementary data}

Supplementary data associated with this article can be found, in the online version, at http://dx.doi.org/10.1016/j.foodchem.2017. 06.129 .

\section{References}

Arya, A., Looi, C. Y., Wong, W. F., Noordin, M. I., Nyamathull, S., Mustafa, M. R., \& Mohd, M. A. (2013). In vitro antioxidant, PTP-1B inhibitory effects and in vivo hypoglycemic potential of selected medicinal plants. International Journal of Pharmacology, 9(1), 50-57. http://dx.doi.org/10.3923/ijp.2013.50.57.

Chandrasekara, A., Rasek, O. A., John, J. A., Chandrasekara, N., \& Shahidi, F. (2016), Solvent and extraction conditions control the assayable phenolic content and antioxidant activities of seeds of black beans, canola and millet. Journal of the American Oil Chemists' Society, 93, 275-283.

Cvjetko, M., Lepojević, Ž., Zeković, Z., Vidović, S., \& Milošević, S. (2009). Antioxidant properties of rapeseed. Zbornik radovaTehnološkog Fakulteta U Leskovcu (Serbia), 19, 27-33.

de Camargo, A. C., Regitano-d'Arce, M. A. B., Biasoto, A. C. T., \& Shahidi, F. (2014), Low molecular weight phenolics of grape juice and winemaking byproducts: Antioxidant activities and inhibition of oxidation of human low-density lipoprotein cholesterol and DNA strand breakage. Journal of Agricultural and Food Chemistry, 62(50), 12159-12171.

Dixon, R. A., \& Paiva, N. L. (1995). Stress-induced phenylpropanoid metabolism. The Plant Cell, 7(7), 1085-1097.

Fang, J., Reichelt, M., Hidalgo, W., Agnolet, S., Schneider, B., Nesi, N., ... Stauber, E. (2012). Tissue-specific distribution of secondary metabolites in rapeseed (Brassica napus L.). PLoS One, 7(10), e48006.

Gao, C., Tian, C., Zhou, R., Zhang, R., \& Lu, Y. (2014). Phenolic composition, DNA damage protective activity and hepatoprotective effect of free phenolic extract from Sphallerocarpus gracilis seeds. International Immunopharmacology, 20(1), 238-247.

Haque, E., Javed, H., Azimullah, S., Abul Khair, S. B., \& Ojha, S. (2015). Neuroprotective potential of ferulic acid in the rotenone model of Parkinson's disease. Drug Design, Development and Therapy, 9, 5499.

Hassas-Roudsari, M., Chang, P. R., Pegg, R. B., \& Tyler, R. T. (2009). Antioxidant capacity of bioactives extracted from canola meal by subcritical water, ethanolic and hot water extraction. Food Chemistry, 114(2), 717-726.

Huang, D., Ou, B., Hampsch-Woodill, M., Flanagan, J. a., \& Prior, R. L. (2002). HighThroughput assay of oxygen radical absorbance capacity (ORAC) using a multichannel liquid handling system coupled with a microplate fluorescence reader in 96-well format. Journal of Agricultural and Food Chemistry, 50(16), 4437-4444. http://dx.doi.org/10.1021/jf0201529.

Huang, D., Ou, B., Prior, R. L., \& Rior, R. O. L. P. (2005). The chemistry behind antioxidant capacity assays. Journal of Agricultural and Food Chemistry, 53(6), 1841-1856.

Isa, N. M., Abdelwahab, S. I., Mohan, S., Abdul, A. B., Sukari, M. A., Taha, M. M. E., ... Mustafa, M. R. (2012). In vitro anti-inflammatory, cytotoxic and antioxidant activities of boesenbergin A, a chalcone isolated from Boesenbergia rotunda (L.) (fingerroot). Brazilian Journal of Medical and Biological Research, 45(6), 524-530.

Jara-Palacios, M. J., González-Manzano, S., Escudero-Gilete, M. L., Hernanz, D., Dueñas, M., González-Paramás, A. M., ... Santos-Buelga, C. (2013). Study of zalema grape pomace: Phenolic composition and biological effects in Caenorhabditis elegans. Journal of Agricultural and Food Chemistry, 61(21), 5114-5121.

Jun, H.-I., Wiesenborn, D. P., \& Kim, Y.-S. (2014). Antioxidant activity of phenolic compounds from canola (Brassica napus) seed. Food Science and Biotechnology, 23(6), 1753-1760. 
Kim, D. H., Yoon, B. H., Jung, W. Y., Kim, J. M., Park, S. J., Park, D. H., ... Ryu, J. H. (2010). Sinapic acid attenuates kainic acid-induced hippocampal neuronal damage in mice. Neuropharmacology, 59(1-2), 20-30.

Kortesniemi, M., Vuorinen, A. L., Sinkkonen, J., Yang, B., Rajala, A., \& Kallio, H. (2015). NMR metabolomics of ripened and developing oilseed rape (Brassica napus) and turnip rape (Brassica rapa). Food Chemistry, 172, 63-70.

Kostadinovic-Velickovska, S., \& Mitrev, S. (2013). Characterization of fatty acid profile, polyphenolic content and antioxidant activity of cold pressed and refined edible oils from macedonia. Journal of Food Chemistry and Nutrition, 1(1), $16-21$.

Kroon, P. A., Faulds, C. B., Ryden, P., Robertson, J. A., \& Williamson, G. (1997). Release of covalently bound ferulic acid from fiber in the human colon. Journal of Agricultural and Food Chemistry, 45, 661-667.

Krygier, K., Sosulski, F., \& Hogge, L. (1982). Free, esterified, and insoluble-bound phenolic acids. 2. Composition of phenolic acids in rapeseed flour and hulls. Journal of Agricultural and Food Chemistry, 30(2), 334-336.

Kwon, S.-H., Kim, M.-J., Ma, S.-X., You, I.-J., Hwang, J.-Y., Oh, J.-H., ... Jang, C.-G. (2012). Eucommia ulmoides Oliv. Bark. protects against hydrogen peroxideinduced neuronal cell death in SH-SY5Y cells. Journal of Ethnopharmacology, 142 (2), 337-345.

Lin, L., Allemekinders, H., Dansby, A., Campbell, L., Durance-Tod, S., Berger, A., \& Jones, P. J. (2013). Evidence of health benefits of canola oil. Nutrition Reviews, 71 (6), 370-385.

Liu, Q., Wu, L., Pu, H., Li, C., \& Hu, Q. (2012). Profile and distribution of soluble and insoluble phenolics in Chinese rapeseed (Brassica napus). Food Chemistry, 135 (2), 616-622.

Neacsu, M., McMonagle, J., Fletcher, R. J., Scobbie, L., Duncan, G. J., Cantlay, L., ... Russell, W. R. (2013). Bound phytophenols from ready-to-eat cereals: Comparison with other plant-based foods. Food Chemistry, 141(3), 2880-2886.

Palmieri, D., Aliakbarian, B., Casazza, A. A., Ferrari, N., Spinella, G., Pane, B., ... Palombo, D. (2012). Effects of polyphenol extract from olive pomace on anoxiainduced endothelial dysfunction. Microvascular Research, 83(3), 281-289.

Phani Kumar, G., Navya, K., Ramya, E. M., Venkataramana, M., Anand, T., \& Anilakumar, K. R. (2013). DNA damage protecting and free radical scavenging properties of Terminalia arjuna bark in PC-12 cells and plasmid DNA. Free Radicals and Antioxidants, 3(1), 35-39.

Portilla, O. M., Rivas, B., Torrado, A., Moldes, A. B., \& Domínguez, J. M. (2008). Revalorisation of vine trimming wastes using Lactobacillus acidophilus and Debaryomyces hansenii. Journal of the Science of Food and Agriculture, 88(13), 2298-2308.

Ravindran, R., \& Jaiswal, A. K. (2016). Exploitation of food industry waste for highvalue products. Trends in Biotechnology, 34(1), 58-69.

Russell, W. R., Gratz, S. W., Duncan, S. H., Holtrop, G., Ince, J., Scobbie, L., ... Flint, H. J. (2011). High-protein, reduced-carbohydrate weight-loss diets promote metabolite profiles likely to be detrimental to colonic health. The American Journal of Clinical Nutrition, 93, 1062-1072.

Russell, W. R., Labat, A., Scobbie, L., Duncan, G. J., \& Duthie, G. G. (2009). Phenolic acid content of fruits commonly consumed and locally produced in Scotland. Food Chemistry, 115(1), 100-104.
Russell, W. R., Scobbie, L., Labat, A., \& Duthie, G. G. (2009). Selective bio-availability of phenolic acids from Scottish strawberries. Molecular Nutrition \& Food Research, 53(S1), S85-S91.

Saeidnia, S., \& Gohari, A. R. (2012). Importance of Brassica napus as a medicinal food plant. Journal of Medicinal Plants Research, 6(14), 2700-2703.

Sagdic, O., Ozturk, I., Ozkan, G., Yetim, H., Ekici, L., \& Yilmaz, M. T. (2011). RP-HPLCDAD analysis of phenolic compounds in pomace extracts from five grape cultivars: Evaluation of their antioxidant, antiradical and antifungal activities in orange and apple juices. Food Chemistry, 126(4), 1749-1758.

Sun, C., Wu, Z., Wang, Z., \& Zhang, H. (2015). Effect of ethanol/water solvents on phenolic profiles and antioxidant properties of Beijing propolis extracts. Evidence-Based Complementary and Alternative Medicine: eCAM, 2015, 595393.

Szydłowska-Czerniak, A. (2013). Rapeseed and its products-sources of bioactive compounds: A review of their characteristics and analysis. Critical Reviews in Food Science and Nutrition, 53(4), 307-330.

Szydłowska-Czerniak, A., Bartkowiak-Broda, I., Karlović, I., Karlovits, G., \& Szłyk, E. (2011). Antioxidant capacity, total phenolics, glucosinolates and colour parameters of rapeseed cultivars. Food Chemistry, 127, 556-563.

Szydłowska-Czerniak, A., Trokowski, K., Karlovits, G., \& Szłyk, E. (2010). Determination of antioxidant capacity, phenolic acids, and fatty acid composition of rapeseed varieties. Journal of Agricultural and Food Chemistry. 58(13), 7502-7509.

Thiyam, U., Kuhlmann, A., Stöckmann, H., \& Schwarz, K. (2004). Prospects of rapeseed oil by-products with respect to antioxidative potential. Comptes Rendus Chimie, 7(6-7), 611-616.

Thiyam, U., Stöckmann, H., Zum Felde, T \& Schwarz, K. (2006). Antioxidative effect of the main sinapic acid derivatives from rapeseed and mustard oil by-products. European Journal of Lipid Science and Technology, 108(3), 239-248.

Wagner, H. (2011). Synergy research: Approaching a new generation of phytopharmaceuticals. Fitoterapia, 82(1), 34-37.

Wanasundara, U., Amarowicz, R., \& Shahidi, F. (1994). Isolation and identification of an antioxidative component in canola meal. Journal of Agriculture and Food Chemistry, 42, 1285-1290.

Waterhouse, A. L. (2003). Determination of total phenolics. In R. E. Wrolstad, T. E. Acree, E. A. Decker, M. H. Penner, D. S. Reid, S. J. Schwartz, C. F. Shoemaker, D. M. Smith, \& P. Sporns (Eds.), Current Protocols in Food Analytical Chemistry. Hoboken, NJ, USA: John Wiley \& Sons, Inc..

Wei, Q.-Y., Zhou, B., Cai, Y.-J., Yang, L., \& Liu, Z.-L. (2006). Synergistic effect of green tea polyphenols with trolox on free radical-induced oxidative DNA damage. Food Chemistry, 96(1), 90-95.

Wijngaard, H. H., Rößle, C., \& Brunton, N. (2009). A survey of Irish fruit and vegetable waste and by-products as a source of polyphenolic antioxidants. Food Chemistry, 116(1), 202-207.

Zou, Y., Kim, A. R., Kim, J. E., Choi, J. S., \& Chung, H. Y. (2002). Peroxynitrite scavenging activity of sinapic acid (3,5-dimethoxy-4-hydroxycinnamic acid) isolated from Brassica juncea. Journal of Agricultural and Food Chemistry, 50(21) 5884-5890. 